
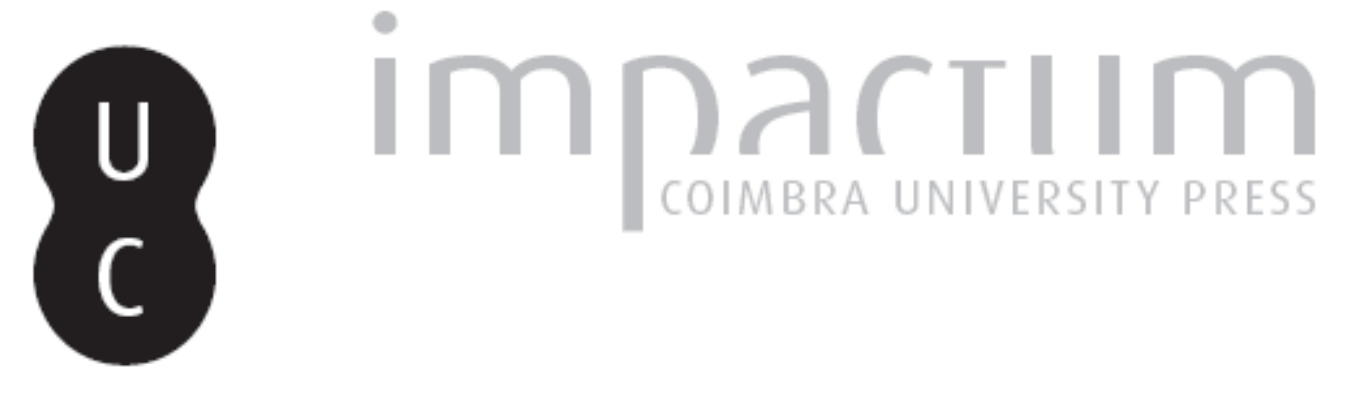

\title{
Poemas que falam para estátuas silenciosas
}

\section{Autor(es): $\quad$ Nogueira, Adriana Freire}
Publicado por: Associação Portuguesa de Estudos Clássicos; Instituto de Estudos Clássicos
URL persistente:
URI:http://hdl.handle.net/10316.2/30408
DOI:
DOI:http://dx.doi.org/10.14195/0872-2110_52_17

Accessed : $\quad$ 26-Apr-2023 16:04:06

A navegação consulta e descarregamento dos títulos inseridos nas Bibliotecas Digitais UC Digitalis, UC Pombalina e UC Impactum, pressupõem a aceitação plena e sem reservas dos Termos e Condições de Uso destas Bibliotecas Digitais, disponíveis em https://digitalis.uc.pt/pt-pt/termos.

Conforme exposto nos referidos Termos e Condições de Uso, o descarregamento de títulos de acesso restrito requer uma licença válida de autorização devendo o utilizador aceder ao(s) documento(s) a partir de um endereço de IP da instituição detentora da supramencionada licença.

Ao utilizador é apenas permitido o descarregamento para uso pessoal, pelo que o emprego do(s) título(s) descarregado(s) para outro fim, designadamente comercial, carece de autorização do respetivo autor ou editor da obra.

Na medida em que todas as obras da UC Digitalis se encontram protegidas pelo Código do Direito de Autor e Direitos Conexos e demais legislação aplicável, toda a cópia, parcial ou total, deste documento, nos casos em que é legalmente admitida, deverá conter ou fazer-se acompanhar por este aviso. 


\section{Boletim de}

\section{Estudos Clássicos}

Associação Portuguesa de Estudos Clássicos Instituto de Estudos Clássicos

Coimbra

Dezembro de 2009 


\section{POEMAS QUE FALAM PARA ESTÁTUAS SILENCIOSAS ${ }^{1}$}

A poesia ecfrástica de Sophia de Mello Breyner Andresen: dois poemas

A poesia de Sophia de Mello Breyner Andresen tem um forte cariz ecfrástico, considerando como tal quer os poemas que assim se assumem, como é o caso dos que aqui vou tratar, quer aqueles a cujas écfrases poderíamos chamar de ficcionais ou imaginárias ${ }^{2}$, isto é, aqueles em que as écfrases remetem para obras de arte que consideramos inexistentes.

Nos poemas que escolhi, V (O Auriga) e VI (Antinoos de Delphos), da parte II - Delphica, da obra Dual, dois elementos evidentes contribuem para inscrever os poemas na longa ${ }^{3}$ tradição ecfrástica, como seja o título, que em ambos remete para duas estátuas ainda hoje passíveis de ser vistas, e a indicação do sítio onde se encontram: Delfos. Esta filiação toponímica está triplamente assertada no poema VI, como se pode verificar

1) no próprio nome do poema - Antínoo de Delphos - que remete para a estátua assim conhecida, que se encontra no Museu daquela cidade, em que a menção ao local permite que não se confunda esta com qualquer outra com o mesmo nome ${ }^{4}$;

1 O nome deste artigo glosa o título do livro de John Hollander The Gazer's Spirit: the Poems Speaking to Silent Work of Art (de 1995, Chicago: Chicago Press).

2 Esta última proposta foi a adoptada por Carlos A. Martins de Jesus (no artigo «O melhor dos pintores. A poética da ekphrasis nos Anacreontea», Boletim de Estudos Clássicos 50, pp.13-26), numa tradução do termo «notional», estabelecido por J. Hollander em 1988, num artigo retomado, em 1995, no livro (p.xii) indicado na nota supra. Hollander (1995:4) define «notional ecphrasis» como «verbal representation of a purely fictional work of art».

3 A écfrase mais antiga da literatura grega (e por demais citada) é do escudo de Aquiles (Homero, Ilíada, XVIII, 478-608).

4 Como o Antínoo Farnese, do Museu de Nápoles (Museo Archeologico Nazionale di Napoli), o Antínoo Altemps (Palazzo Altemps, Museo Nazionale Romano, Roma), o Antínoo do Prado (Museo del Prado, Madrid), o Antínoo Lansdowne (Fitzwilliam Museum, Cambridge), ou os diversos Antínoos que se encontram no Museu do Louvre, em Paris, entre outros. Favorito do imperador 
2) na designação da parte do livro em que se insere - Delphica -, evocando o carácter profético da pitonisa de Apolo;

3) na datação - Delphos, Maio de 1970, que funciona como elemento intensificador da vontade de demonstrar o carácter verídico da peça descrita. Porém, a datação funciona também como marca antitética da consciência da transitoriedade e da vontade de permanência: o narrador ${ }^{5}$ grava no poema as marcas de um tempo inexoravelmente transitório.

Começo pelo poema $V$ (O Auriga), pois a ordem em que ambos são apresentados sugere uma continuidade, confirmada, aliás, no último verso do poema VI (Antinoos de Delphos), onde a posição/localização da estátua, no espaço do museu, é apontada, sendo o Auriga mencionado acompanhado de um adjectivo precedido de um determinante definido, de modo a que não haja dúvidas quanto à sua identificação: Entre o austero Auriga e a arquitrave quebrada. No poema $V$, o Auriga não é designado directamente como austero, mas por metonímia (ou por hipálage) esse é o atributo com que é classificado o seu aprumo, aliás, o «Aprumo de prumo da tua [sua] juventude».

O poeta fala para uma estátua silenciosa, mas esse silêncio é apenas a ausência das palavras e dos sons, pois a estátua diz muito de si. Aliás, este verbo («dizer») é usado três vezes no poema: diz (v.3), dizem (v.5 e v.10). A estátua mostra, a estátua diz, a estátua olha. A estátua fala pelas palavras do poeta ou o poeta fala-nos através da estátua. Isto é, esta mesma estátua diz, mostra, fita quem a vê, sempre com olhos de esmalte e de ónix, com A longa túnica, com $O$ pulso fino, mas sem, necessariamente, a dimensão simbólica que as palavras do poema lhe atribuem.

O narrador dirige-se à estátua, fazendo com que apreendamos a sua descrição indirectamente, como se estivéssemos a ouvir uma conversa que não nos é dirigida, despertando no leitor um espírito voyeurístico, dado que este "vê» a obra descrita pelas palavras daquele: estamos no texto como assistentes do diálogo que se estabelece entre imagem e palavras, cuja relação ultrapassa o que o metal nos pode dizer.

Adriano, este jovem foi largamente representado na escultura. A estátua de Delfos é uma imagem de culto, entre as muitas que lhe foram erigidas, em vários templos, após a sua prematura morte por afogamento no Nilo.

5 Irei usar «narrador», «poeta» ou mesmo «Sophia», apenas como variatio, referindo-me ao sujeito de enunciação do texto poético. 
A estátua é lida de baixo para cima, como se o observador estivesse num plano inferior, em que o primeiro que vê são os pés:

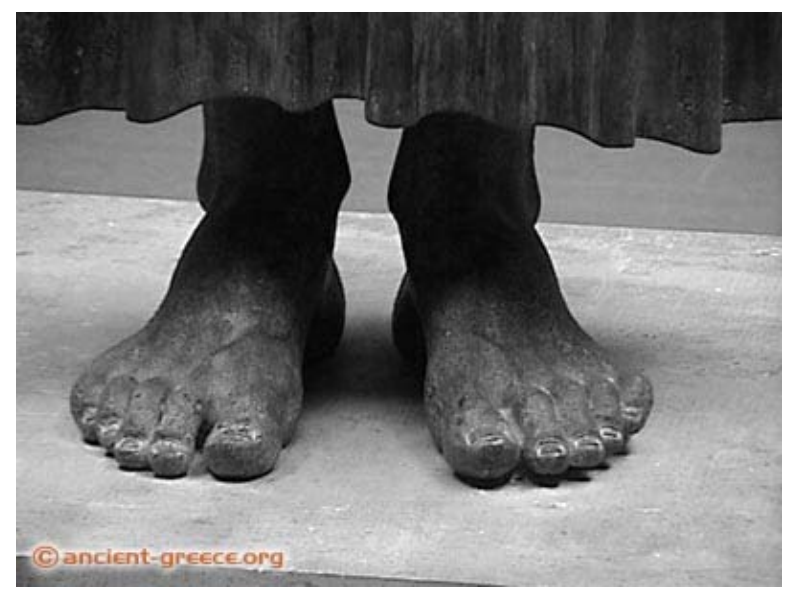

A nudez dos pés que o escultor modelou com amor e minúcia Mostra a pura nudez do teu estar na terra

A estátua eleva-se aos nossos olhos. Medimos o seu 1,80m em cima de um pedestal e notamos o equilíbrio do bronze nuns pés nus, mas seguros, que dão leveza ao conjunto. 


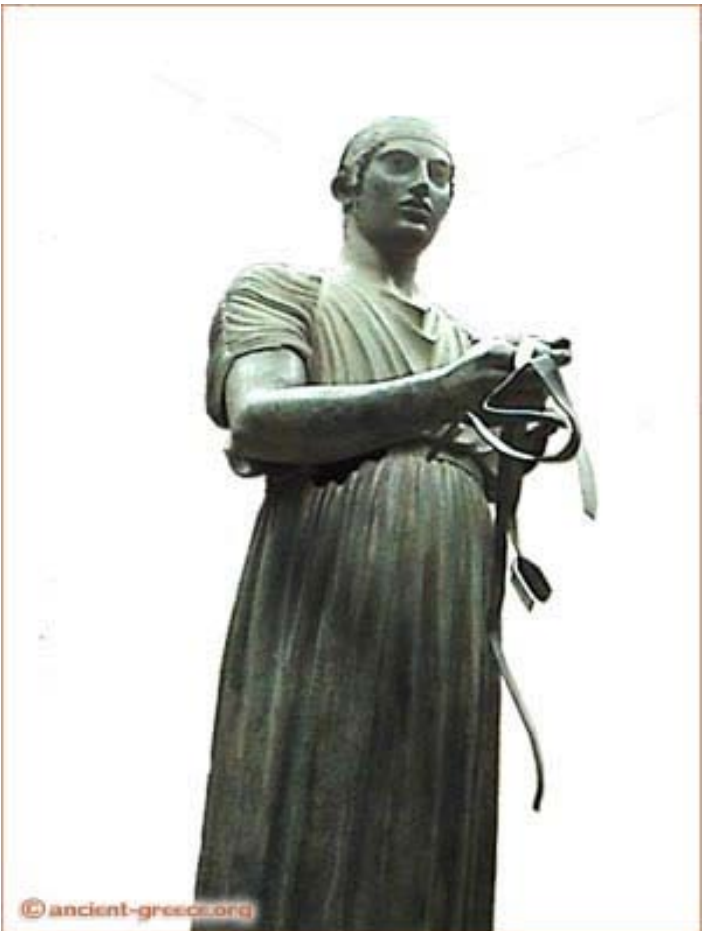

No entanto, os versos seguintes sugerem distância, pois só assim se consegue estimar um todo, na apreciação do comprimento da túnica e das pregas longilíneas. 


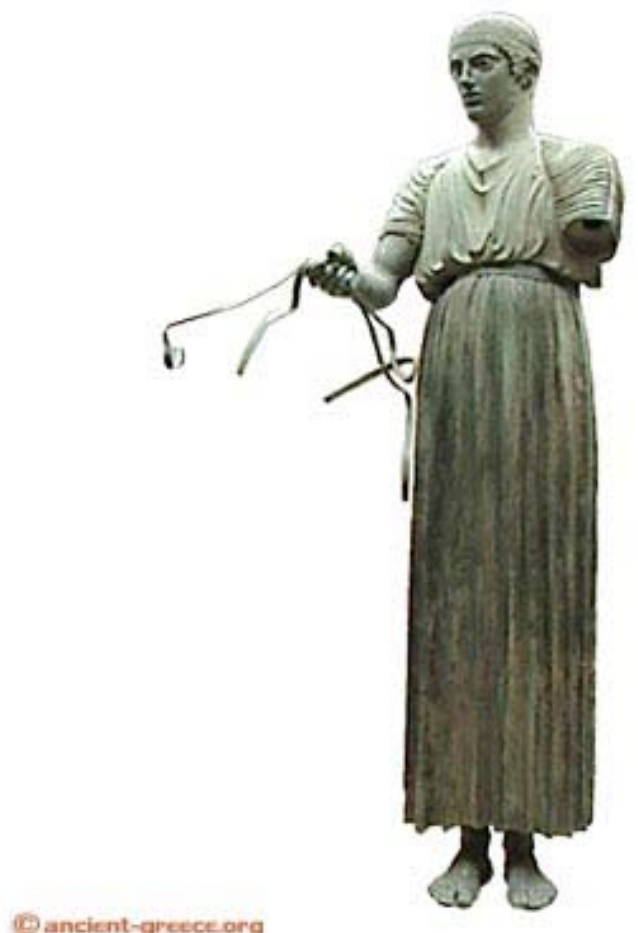

A longa túnica em seu recto cair diz o austero Aprumo de prumo da tua juventude

Estes versos contêm um jogo semântico centrado no adjectivo «recto», em que o sentido denotativo de «direito» se transfere para o metafórico associado a rectidão de carácter, reforçado pela insistência de outros vocábulos do mesmo campo semântico: «austero» e «aprumo», encadeandose este, num outro jogo similar, a "prumo». Também através destes versos nos podemos aperceber de que os olhos de quem vê a estátua não são uns olhos jovens, pois a ausência consciencializa a carência e ambas tornam-se prementes quando confrontadas com a presença: são esses velhos olhos que 
vêem a juventude que (ainda) não conheceu a derrota, que é (ainda) abençoada pelos deuses em que (ainda) acredita.

O poeta quebra, com as palavras, a barreira que nos separa da obra. Numa definição de Krieger (1992:22), «Ekphrasis is the poet's marriage of the two within the verbal art», referindo-se estes «two» ao emblema visual e ao emblema verbal, sobre os quais se diz, ibidem, «The visual emblem and the verbal emblem are complementary languages for seeking the representation of the unrepresentable».

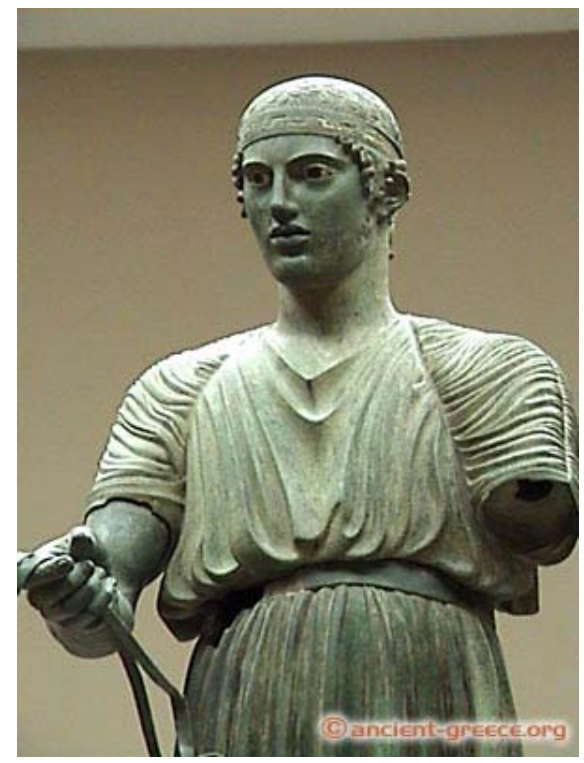

O pulso fino a concisa mão divina dizem

O pensamento rápido e subtil como Athena

$E$ a vontade sensível e serena:

A ti mesmo te guias como a teus cavalos

O pulso é fino e na estabilidade da mão o poeta pressente a semelhança com a divindade, igualando as qualidades do Auriga às da própria deusa Atena. E nós vemos o que o poeta quer que vejamos, o «irrepresentável»: a rapidez e subtileza do pensamento, a sensibilidade, a serenidade, a vontade: que importa (e o que é) a realidade? 


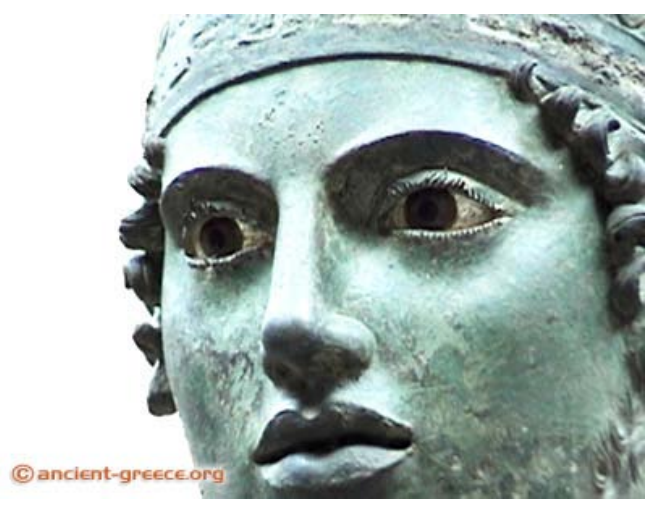

Os beiços de seiva inchados como fruto

Dizem o teu amor da vida extasiado e grave

E sob as tuas pestanas de bronze nos olhos de esmalte e de ónix

Fita-nos a tua paixão tranquila

O teu projecto

De em ti mesmo celebrares a ordem natural do divino

O número imanente.

O poeta tenta minimizar a distância que nos separa da estátua que não vemos: diz-nos o material de que é feita ( $E$ sob as tuas pestanas de bronze nos olhos de esmalte e de ónix), descreve-a recorrendo a comparações (Os beiços de seiva inchados como fruto), hipálages e metáforas (Fita-nos a tua paixão tranquila). Contudo apercebemo-nos de que o poeta fala de si, do seu projecto (não do dele, Auriga), em si mesmo celebrado.

Regressando à proposta de reflexão que apresentei no início, este comentário inclui também o poema VI (Antinoos de Delphos), écfrase da estátua de Delfos e não de nenhuma outra ${ }^{6}$. Contudo, o que aqui se diz e se lhe diz (à estátua), seria válido para muitas outras. A constância da representação pode ser aval da semelhança ao original humano ou à cópia da estátua que oficialmente o representava.

\footnotetext{
6 Cf. nota 4.
} 
Mais uma vez, intrometemo-nos uma conversa, só que esta plena de recordações mais secas. O uso anafórico do possessivo na $2^{\text {a }}$ pessoa deixa bem claro a quem se dirige o narrador:

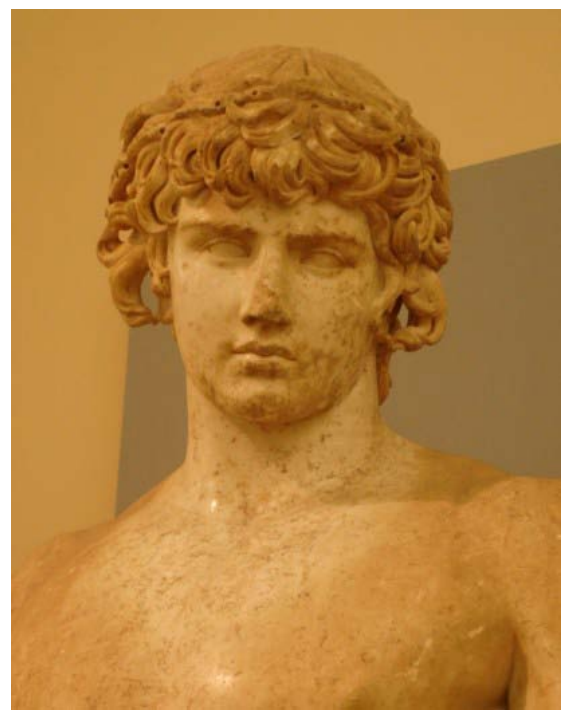

Tua face taurina tua testa baixa

Teus cabelos em anel que sacudias como crina

Teu torso inchado de ar como uma vela

Teu queixo redondo tua boca pesada

Tua pesada beleza

Teu meio-dia nocturno

Pescoço grosso, ombros largos, rosto arredondado, testa tapada pelos caracóis do cabelo. A imagem do touro envia-nos para a força, o ímpeto. A ela se juntam outras imagens de liberdade: a do cavalo à solta, a das velas dos barcos.

Como a memória que nos traz as recordações em soluços, em imagens que escoam indomadas, a secura traduz-se pelo parco uso de verbos: sacudias (v.2), afogaste (v.7), são (v.10), rodeiam (v.11). Começa com um imperfeito, um tempo inacabado. Os anéis do cabelo em desalinho são visíveis na estátua, 
mas faltava-nos o verbo que explica o gesto, o movimento que provoca esse desalinho e que dá vida: Teus cabelos em anel que sacudias como crina.

A écfrase privilegiou o realçar de um movimento circular ao descrever os anéis do cabelo (cabelos em anel), o redondo do queixo (queixo redondo), e ao usar figuras de retórica que o reforçam: o quase quiasmo (Tua boca pesada/Tua pesada beleza), a antítese (Teu meio-dia nocturno). Esta circularidade recapitula a brevidade da vida: breve porque cedo perdida, afogada no Nilo, breve porque transformada em estátua de mármore polido, encerrada num museu.

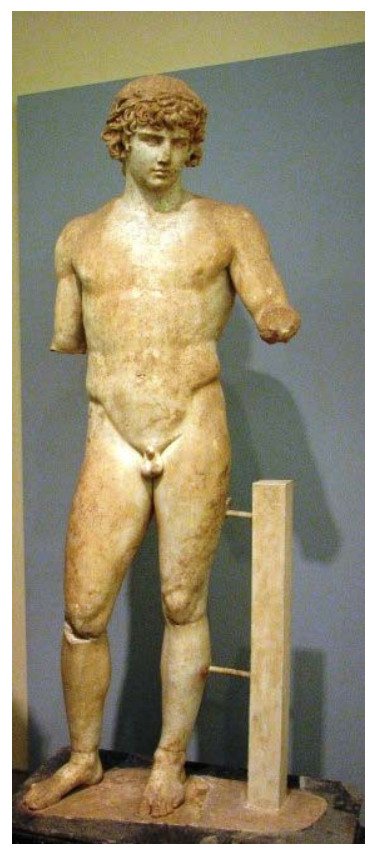

Tua herança, dos deuses que no Nilo afogaste

Tua unidade inteira com teu corpo

Num silêncio de sol obstinado

Agora são de pedra no museu de Delphos

Onde montanhas te rodeiam como incenso

Entre o austero Auriga e a arquitrave quebrada. 
Esta é uma visão desencantada. No seu tempo, Antínoo foi identificado com os deuses, principalmente com Osíris ${ }^{7}$, também ele morto e ressuscitado. A referência a Tua unidade inteira com teu corpo lembra os pedaços em que o deus egípcio foi cortado, mas estes deuses (a sua herança divina) morreram com o jovem, são aqueles deuses que no Nilo afogaste. Morto o divino, resta o enterro num espaço museológico, encaixado entre montanhas, rodeado de outros objectos (igualmente) quebrados.

Ao fazer este comentário, surgiram-me várias interrogações: se entre a data que Sophia nos indica (1970) e hoje (2009) se tivessem perdido aquelas estátuas (e supondo uma catástrofe tal que não tivessem sobrevivido imagens), como saberíamos que os seus poemas não se tratavam de uma «representação puramente ficcional» ${ }^{8}$ e, portanto, de uma écfrase ficcional? Até que ponto interessa saber se a obra descrita existe fora do poema ou se faz parte unicamente do universo do poeta, que a usa como recurso retórico? Que nos interessa que, afinal, as pestanas do Auriga sejam de cobre e não de bronze? Ou que a estátua não tenha um braço ou não existam nenhuns cavalos para serem guiados? Esse interesse puramente histórico apenas importa para compreender as opções que o poeta tomou na sua criação retórica, e porque a estátua de Sophia é aquela que as palavras dizem ao falarem para ela (e para além dela), a concepção de «notional» abarca, assim, toda a representação verbal, diluindo-se na de simples écfrase.

Termino, ciente de que a minha leitura é ela, também, uma écfrase, citando Peter Wagner (1996:14) que, quando define ekphrasis como a representação verbal de uma obra de arte, considera que «representação verbal» tem de ser entendida como «all verbal commentary/writing (poems, critical assessments, art historical accounts) on images».

\section{Bibliografia}

HEFFERNAN, James. 1993. Museum of words: the poetics of ekphrasis from Homer to Ashbury. Chicago: University of Chicago Press.

HOLLANDER, John. 1995. The Gazer's Spirit: Poems Speaking to Silent Works of Art. Chicago: University of Chicago Press.

7 Cf. Estátua de Antínoo como Osíris que se encontra no Museu do Vaticano, proveniente da Villa Adriana, em Tivoli.

${ }^{8}$ Cf. nota 2. 
KRIEGER, Murray. 1992. Ekphrasis. The Illusion of the Natural Sign. Baltimore and London: The John Hopkins University Press.

PETRAKOS, Basil. 1977. Delphi. Athens: Clio Editions.

SAKOULAS, Thomas. Charioteer of Delphi. Ancient-Greece.org. 9/11/2009 <http://www.ancient-greece.org/art/chiarioteer.html>.

WAGNER, Peter. 1996. Icons, Texts, Iconotexts: Essays on Ekphrasis and Intermediality. Berlin, New York: W. de Gruyter.

ADRIANA FREIRE NOGUEIRA 